\title{
TYPOLOGIES OF INSTITUTIONAL COMMUNICATION
}

\author{
Gabriela IOSIF \\ National Institute for R\&D in Electrical Engineering ICPE-CA \\ e-mail: gabyiosif@yahoo.com
}

\begin{abstract}
From the point of view of Durkheim, institutions are ways of acting, feeling and thinking, expressing any social act. Institutions have stringent action on the individual, have its own existence, independent of individual manifestations, which are distinctive for a given group, being accepted by all members. Types of social institutions are economic institutions, educational, political, cultural and family. Within institutions, communication is an inherent phenomenon.

For Katz and Kahn "communication is a social process of great relevance to the functioning of each group, organization or society, "the very essence of the social system or organization. The organizational structure provides stability for human communication and facilitates administrative tasks. (Rogers Everett M. and Agarwala-Rogers Rekha, 1976, p. 6). Therefore, an effective institutional communication adds value to any institution.
\end{abstract}

Keywords: Institutional communication, efficiency, common purposes, value, succes, interrelations

JEL Classification: $\mathrm{D}_{23}$

\section{Introduction}

The paper aims to bring into evidence the diversity of typologies of communication and the importance of an effective communication in any institutional environment.

Communication is an important aspect; it is the soul of the organization. If we could remove communication, we would not have an organization any more. From an open perspective, an organization is an elaborate set of interconnected communication channels designed to receive, sort and analyse information from the environment and send messages processed back into the environment (Rogers Everett M. and Agarwala-Rogers Rekha, 1976, p. 7).

Each institution controls a certain area of institutionalized social life. Institutions have different regulative principles, values, norms, sanctions. In the middle of them are social form of groups and specialized roles to fulfil specific functions. From bringing together all these constituents, values, norms, sanctions, roles and social groups specialized technical and material resources results the social organization of the institution. Organizations were created to achieve some ends, in which people interact to achieve other ends. 
Organizations occurred while the individual work efficiency has become increasingly dependent on the results of specialized people, due to the division of people from the same field. Organization is always specialized. It has a mission, which is associated with certain objectives. Differentiation of missions and objectives is associated with technical expertise (Vlăsceanu Mihaela, 2003, p. 88).

In terms of legislation, institutions consist of a set of rules defining recurring patterns of behaviour and social networking. Institutions function is to decide the behaviour of individuals and groups. Institutions are considered even internalized norms by the social actors in order to guide their behaviour and give them a sense of appropriateness of behaviour to a set of values compatible with. In the last sense, institutions are considered as components of common symbolic systems, of the cognitive and cultural processes of social life (Vlăsceanu Mihaela, 2002, pp. 159160).

All activities inside and outside institutions implies communication. Highlighting the complexity of the phenomenon of institutional communication is shown by the multitude of types of communication within institutions, how they function and interact within institutions.

Because of the importance and complexity, institutional and organizational communication, aspects and specific implications enjoyed a rich professional attention from authors in the country, but especially abroad.

\section{Current context of institutional communication}

Besides the public sector who is under the control of government agencies, the private sector, with the multitude of private organizations that operates on market rules, there are non-profit sector expanding by the day in various areas of social life: education health, environment, culture, artistic literary associations and societies, civic organizations, clubs, foundations.

Within these institutions operates the working groups. Human interactions can be ordered in a structure that differs from one organization to another, but the success of an organization in achieving its objectives depends on the quality of interactions and communication inside.

Interaction between members of the organization varies depending the type of organization, its size and, not least, the communication process. No matter the structure of organizations, formal or informal, people interact with each other. If in the informal plan relationships between people are spontaneous, undefined clear, in the formal plan relationships are stable and relatively inflexible, setting the objectives hierarchy, authority relations, communication channels. However, even within formal organizations functions informal groups as a means of cohesion and communication between individuals (Vlăsceanu Mihaela, 1993, pp. 20-23).

The meanings of the concept of communication have diversified over time, especially as a result of modern communication techniques.

Regarding the classification of communication, it can be direct, through direct contacts between people, and indirect, that rely on transmission of information techniques (Drăgan Ioan, 2007, vol. 1, p. 17).

Communication can take place on many levels. It can be verbal when uses speaking and writing, non-verbal when is based on gestures, intrapersonal, when involves one person, interpersonal when involves at least two people carrying out 
an exchange of ideas, group communication when talking about a working session between co-workers, mass communication when uses a technical support to broadcast messages and publicized communication when we serve a technological tool (Rieffel Remy, 2001, p. 18).

Oral communication refers to messages that circulate, allowing other people to have something to say about us (Hall Michael L., 2008, p. 166).

Both verbal and nonverbal communication can be modelled in terms of transmitter, receiver, message, and channel of communication, effect, feedback and context of communication acts. The transmitter is the source of messages. The receiver is the one who get the message. The message has a meaning, which is encoded, transmitted in code, in a system of signs, suitable communications channel, and the receiver decodes the information. Decoding nonverbal messages must consider the cultural context, cultural information associated with the communication act. Some cultures are highly contextual and attaches particular importance of the context in determining the meaning of communication, others are weak contextual (Chelcea Septimiu, Ivan Loredana, Chelcea Adina, 2005, p. 14).

Intrapersonal communication is going on within each individual, involving thoughts, feelings and how others are perceived. Being self-centred individual is both transmitter and receiver.

Interpersonal communication is achieved by multiple people dialogue face to face. Here, important roles are gestures, tone of voice, body posture, feed-back and the distance between interlocutors. Interpersonal communication involves face to face meeting between two participants, for which is excluded any mediated communication, involves two people with varying roles in relation to each other, occurs in both directions, there is always a two-way communication flow and, not least, it is not only about messaging. It involves the creation of symbols, sharing meanings and concern for a specific message (Anghel Petre, 2003, pp. 21-24).

\section{Typologies of institutional communication}

The typologies of institutional communication can be classified according to three criteria: according to the purpose of communication, downward communication, upward communication, communication lateral (horizontal) and cross-communication (diagonal or oblique), by the degree of formalization we distinguish formal communication and informal communication, according to the manner of deployment, organizational communication can be direct communication (personal) and indirect communication (impersonal).

Upward communication takes the form of written reports or information or direct talks in sessions of analysis, professional meetings etc. If it's oral, the upward communication may be distorted by the same factors as downward communication. Upward communication refers to messages that are sent from the lower to the higher hierarchical levels.

Downward communication refers to messages sent from higher levels to lower levels of the hierarchy. Sometimes managers do not know how to make themselves understood by their subordinates. Many managers use a specialized language that can be difficult to be understand by subordinates (Pânişoară IonOvidiu, 2008, pp. 74-76). 
Lateral communication is the flow of information between departments or sectors. Its purpose is to ensure the coordination of activities between the departments of the organization.

Cross communication provides flow circulation of information between people at different organizational levels, without being mediated by middle managers. This communication takes place in the general assemblies of workers, training sessions, and informally at events organized by the organization. Interpersonal communication is a useful form and helps to create a climate of cooperation within the organization. (Păuş Viorica Aura, 2006, pp. 125-126).

Lateral communication refers to messages sent from manager to manager, from the same hierarchical level, from worker to worker. This type of communication facilitates the sharing agreement phenomena, methods and problems, develops employee satisfaction related to work.

Serial communication relates on messages along people. Serial communication problems are the emergence of rumours. This refers to reducing the number of details by relaying the message, making it easier to simplify submission to another person and giving the details in the message to others in order to rebuild their own professional attitudes (Pânişoară Ion-Ovidiu, 2008, pp. 74-76).

The meeting is the institutionalized dialogue form of an organization. It is conducted according to precise rules in order to achieve a goal that cannot be achieved by any other form of oral or written communication. In sessions, there are exchanged oral words or opinions. Through the organization of a meeting, the manager communicates respect and the way in which he takes the responsibility.

Formal communication ensure the information necessary to achieve the objectives of the organization and its proper functioning: orders indicated hierarchically. Failure in doing this involves sanctions. Compliance with this type of communication takes, especially, the manager exercising.

Informal communication occurs within the working groups, helps the communication between the members of the organization and ensures a climate of harmony based on the understanding of the staff, giving values to the organization. This communication contributes even to the dissemination of positive or negative image of the organization outside (Păuş Viorica Aura, 2006, p. 126).

Informal communication is the basis of cognitive dissonance, because usually, the employees decide the source from which they receive information. Thus, there is a psychological mechanism that rejects information that is not consistent with their own beliefs, which can reach up to ignoring the views exposed (Nedelea Alexandru, 2006, p. 132).

Direct communication occurs when the transmitter and receiver are face to face, may be one-sided when is descending and bilateral when expects feedback from the receiver. A form of direct communication is the professional communication between collaborators, which include informal personal communication side.

Indirect communication can be mutual, when the channel of communication is the phone or one part only through written documents, film, television, radio, speeches lines and any form of communication that does not allow feedback. A mixed type of indirect communication is the interactive radio broadcasts or interactive communication on the internet (Păuş Viorica Aura, 2006, p. 126). 


\section{Issues of institutional communication}

In the case of big institutions, the institutional communication is done by formal communication channels and represent the management ideas about who should communicate with whom, in order to solve a problem.

Instead, in the case of the small institutions, formal communication networks are simple and barely noticeable.

The top-down communication flows heavy because the messages are insufficient or not clear, or too much, come at a wrong time, are transmitted in a serial way, losing quantitatively the content.

Upward communication message issues are such as distortion problem and differentiated status between employee and boss. The benefits arising from this communication are aspects such as: provides feedback on the accuracy of the received message, indicates how well the management decisions were received, increases the acceptance of the management decisions, prevents new problems and highlight the old ones.

Horizontal communication is represented by the messages between members of the same power with others in the same department or in different areas. Issues that inhibit horizontal communication may be rivalry, differences in specialization, lack of motivation and mental barriers.

Organization involves people interacting to achieve a common goal. Human interactions can be ordered in a structure that differs from one organization to another, but they are the ones that determine the functioning of the organization foundation.

According to Mihaela Vlasceanu, the success or failure of the organization in achieving goals and objectives are closely related to the interactions between members, whether consolidated or not. In other words, the process of interaction can influence the intensity of personal and organizational objectives.

The interaction between the members of the organization is inevitable and varies according with the communicative process. People interact with each other, generating formal and informal relations, spontaneous and inflexible relations, through the communication channels. But, often, the lack of proper communication, differences in values, culture, goals and interests, or an inappropriate leadership represents, for the climate of communication in every organization and institution, disturbing elements.

If the communication mean, like the Palo Alto School, the matrix in which are all human activities, it is impossible not to communicate because every action presupposes and includes sine qua non communication.

This is why a good and efficient institutional communication is an important aspect for any organization.

\section{Conclusions}

Whatever the work, communication is a vital, important aspect. In all institutions and organizations, no matter their form and organization, we can meet, inevitably, the notion of communication. 
Communication occupies most of the working time and at the same time, it is essential for the effective functioning of an organization and successful careers of its members (Adler Ronald B., 1986, p. 5).

In essence, communicating aims the accuracy information of the group members, the formation of opinions, the transmission of ideas, suggestions among group members, performing tasks, making decisions and assessing performance.

Group communication is specific to the organizations or places where people gather to discuss certain topics. Public communication is the form in which representatives of organizations or specialized groups appeal. Mass communication is actually sending messages to a diverse audience. Certainly, all these forms of communication are interrelated, merging with each other (Drăgan Ioan, 2007, pp. 17-18).

Communications within the group are influenced by the quality of the message, the speed and place of communication, meaning: upward, downward, horizontal, oblique communication, group size, spatial position of the group members in the communication process (Tran Vasile, Stănciugelu Irina, 2001, p. 196).

No matter the many types of communication found in the institution, formal, informal, verbal, nonverbal, intrapersonal, interpersonal, upward, downward, lateral, horizontal, serial, direct, indirect, bottom-up and top-below, it is good to create and continuously improve procedures for communication, because communication it's a rapidly growing phenomenon, which involves, obviously, the developing of methods and procedures for the development of institutional communication.

To be effective, communication must express coherent institutional goals of the organization so that they can be understood and shared by all members of the organization and even the society, being redefined depending on the socio-political dynamics. In this way, the optimization of the communication contributes to positive and lasting effects in people's work. The areas where the impact of communication is a key element are efficiency, cohesion and trust among the members of the organization and, last but not least, the efficiency of their actions (Minulescu Mihaela, 2004, pp. 2-5).

In this context, communication in organizations is an important factor that determines at micro level the purpose of our actions and at macro level the organizational excellence.

Therefore, institutions and organizations would be better to have a wellorganized system of communication in order to improve business, by developing procedures to increase and control the institutional communication.

Through the development of information and communication technologies, which are present in each institution, it is possible to transmit large amounts of information and, ultimately, to develop a knowledge-based management. On the other hand, new technologies have created new ways of organizing and action in institutions, by abandoning hierarchies for communication networks. Through the development of communications, due to the evolution of internet, new forms of communication appeared in which people can be in the situation of talking one to many or many to many (Gârdan Adrian Daniel, Geangu Iuliana Petronela, 2013, p. 81). 
This aspect implicitly leads to the transition from the organizations structured vertically to the organizations structured horizontally. These new forms of communication involve the democratization of the organizational life, the whole activity being centred especially on knowledge and communication and less on control. So, the control relationships and the vertical communication are being replaced with the lateral relations (Vlăsceanu Mihaela, 2005, p. 26).

\section{REFERENCES}

1. Adler, Ronald B. (1986), Communicating at Work: Principles and Practices for Business and the Professions, Santa Barbara City College, New York: Random House. Aramis.

2. Anghel, Petre (2003), Styles and Methods of Communication, Bucharest:

3. Chelcea, Septimiu, Ivan, Loredana, Chelcea, Adina (2005), Nonverbal Communication: Gestures and Posture, Bucharest: Comunicare.ro.

4. Drăgan, Ioan (2007), Communication - Paradigms and Theories, vol. 1, Bucharest: Rao.

5. Gârdan, Adrian-Daniel, Geangu, Iuliana-Petronela (2013), Peculiarities of Marketing Communications in Cultural Marketing, Annals of Spiru Haret University, Economic Series, vol. 4(13), issue 3, pp. 77-83.

6. Hall, Michael L. (2008), The Magic of Communication. Exploring the Structure and Meaning of Language, Bucharest: Excalibur

7. Minulescu, Mihaela (2004), Organizational Communication, Bucharest, pp. 2-5, http://www.slideshare.net/Elida82/comunicare-organizationala-m-minulescu

8. Nedelea, Alexandru (2006), Marketing in Public Administration, Bucharest: Didactică şi Pedagogică.

9. Păuş, Viorica Aura (2006), Communication and Human Resources, Iasi: Polirom.

10. Pânişoară, Ion-Ovidiu (2008), Efficient Communication, Iasi: Polirom.

11. Rieffel, Remy (2001), An Introduction to the Written and Spoken Press, coordinator Claude Jean Bertrand, Iasi: Polirom.

12. Rogers, Everett M., Agarwala-Rogers, Rekha (1976), Comunication in Organizations, The Free Press, a Division of Macmillan Publishing Co., Inc., New York, Collier Macmillan Publishers, London.

13. Tran, Vasile, Stănciugelu, Irina (2001), The Theory of Communication, Bucharest: SNSPA.

14. Vlăsceanu, Mihaela (2003), Organizations and Organizational Behaviour, Iasi: Polirom.

15. Vlăsceanu, Mihaela (2002), Organizations and the Organization Culture, Bucharest: Trei.

16. Vlăsceanu, Mihaela (1993), Psychosociology of Organizations and Management, Bucharest: Paideia.

17. Vlăsceanu, Mihaela (2005), Organization: Design and Change, Bucharest: Comunicare.ro 
